Natalia Pamuła-Cieślak

Instytut Informacii Naukowej i Bibliologii

Uniwersytet Mikołaja Kopernika w Toruniu e-mail: napa@umk.pl

\title{
Otwartość polskich czasopism indeksowanych w Directory of Open Access Journal - w kierunku modelu gratis czy libre?
}

STRESZCZENIE: Otwarty dostęp do treści naukowych oznacza likwidację barier cenowych i większości ograniczeń prawnoautorskich. Może mieć on wymiar gratis, gdzie likwidacja kosztów dostępu jest jedynym przejawem otwartości, a swobodne korzystanie ograniczone do dozwolonego użytku. Może także przybierać formę dostępu zwaną libre, która poprzez wprowadzenie uregulowań prawnych w postaci licencji wyznacza możliwości użytkowania treści poza dozwolonym użytkiem. Autorka prześledziła sytuację polskich czasopism otwartych rejestrowanych w katalogu Directory of Open Access Journal w zakresie stosowania licencji rekomendowanych przez redakcję katalogu oraz Ministerstwo Nauki i Szkolnictwa Wyższego, szukając odpowiedzi na pytanie, który z modeli otwartości bliższy jest ich wydawcom.

SŁowA KLUCzowe: Directory of Open Access Journal, DOAJ, otwarty dostęp, otwarty dostęp gratis, otwarty dostęp libre, licencje Creative Commons, polskie czasopisma naukowe. 


\section{Wprowadzenie}

O

twarty dostęp (ang. open access, dalej: OA) to pojęcie, które pojawiło się już w latach 90. XX w. ${ }^{1} \mathrm{w}$ kontekście szerokiego i nieodpłatnego udostępniania treści naukowych online. Definicji tego terminu jest wiele, jednak trzy z nich - poparte międzynarodowymi ustaleniami mają szczególne znaczenie. Są to definicje zawarte w dokumentach: „Deklaracja Budapeszteńska” („Budapest Open Access Initiative”) z lutego 2002 r., „Deklaracja z Bethesda” („Bethesda Statement on Open Access Publishing”) z czerwca 2003 r. oraz „Deklaracja Berlińska” („Berlin Declaration on Open Access to Knowledge in the Sciences and Humanities") z października 2003 r. Wszystkie trzy przywołane akty sprowadzają definiowanie otwartego dostępu do udostępniania treści naukowych w sieci internetowej bez barier cenowych i większości ograniczeń licencyjnych oraz prawnoautorskich ${ }^{2}$.

Z pojęciem otwartego dostępu wiążą się także terminy złotego (czasopiśmienniczego) i zielonego (repozytoryjnego) kanału dostępu do treści otwartych. Innymi pojęciami często definiowanymi w publikacjach dotyczących otwartości jest rozumienie terminów open access gratis i open access libre. Oba wiążą się z prawnoautorskimi aspektami funkcjonowania treści otwartego dostępu - otwarty dostęp gratis oznacza bezpłatne umieszczanie otwartych treści w Internecie. Brak dodatkowych uregulowań sprawia, że bywa on nazywany „słabym”. Użytkownik może wykorzystać treści otwarte w ten sposób wyłącznie w granicach dozwolonego użytku, jako że zdjęto z nich wyłącznie restrykcję kosztów dostępu do treści. Open access libre oznacza zaś dodatkowe uwarunkowania prawne, które pozwalają użytkownikowi na legalne korzystanie z udostępnionych treści szerzej, niż warunkuje to dozwolony użytek. Najczęściej przyjmowanym rozwiązaniem jest zastosowanie jednej z sześciu licencji Creative Commons [dalej: CC].

${ }^{1}$ B. Bednarek-Michalska, Kalendarium OA w Polsce [online] [dostęp 31 marca 2017]. Dostępny w World Wide Web: http://uwolnijnauke.pl/kalendarium-oa-w-polsce/; Timeline before 2000 [online] [dostęp 31 marca 2017]. Dostępny w World Wide Web: http:// oad.simmons.edu/oadwiki/Timeline_before_2000.

2 P. Suber, Otwarty dostęp, Warszawa 2014, s. 19-20. 


\section{Cel badań}

Celem niniejszego tekstu jest zaprezentowanie wyników analizy sytuacji polskich czasopism otwartych indeksowanych w Directory of Open Access Journal [dalej: DOAJ] względem definicji OA gratis i libre, nowych wytycznych pojmowania otwartego dostępu przez redakcję tego katalogu oraz sugestii zawartych w dokumencie Kierunki rozwoju otwartego dostępu do publikacji i wyników badań naukowych w Polsce opublikowanym przez Ministerstwo Nauki i Szkolnictwa Wyższego [dalej: MNiSW], w którym wskazano dwie, spośród sześciu licencji Creative Commons, jako przejaw otwartego dostępu w modelu libre i maksymalizujące korzyści z otwartości. Wskazane przez MNiSW licencje to CC BY (uznanie autorstwa) oraz CC BY-SA (uznanie autorstwa - na tych samych warunkach) ${ }^{3}$.

Wcześniejsze badania polskich czasopism otwartych były prowadzone i publikowane ${ }^{4}$. Jako źródło wiedzy o nich wskazywany był katalog DOAJ. Interesującej analizy polskich czasopism na podstawie danych pozyskanych z Directory of Open Access Journal dokonali Mirosław Garbacz, Krzysztof Moskwa i Honorata Niemiec z Biblioteki Głównej i Ośrodka Informacji Naukowo-Technicznej Politechniki Wrocławskiej ${ }^{5}$. Zbadali oni sposób dostępu do pełnych tekstów artykułów, informacje o kosztach publikacji w badanych czasopismach, wzorce umów autorskich, wymogi przeniesienia praw autorskich na wydawcę, zasady publikowania i instrukcje dla autorów, zasady publikowania w modelu otwartym oraz deklaracje wydawcy co do przyjętej w czasopiśmie polityki otwartego

${ }^{3}$ Kierunki rozwoju otwartego dostępu do publikacji i wyników badań naukowych w Polsce [online]. Warszawa: Ministerstwo Nauki i Szkolnictwa Wyższego, 2016, 20 s. [dostęp 31 marca 2017]. Dostępny w World Wide Web: http://www.nauka.gov.pl/g2/ oryginal/2016_09/25db3413b93e0da2c7c862a80e687ad1.pdf.

4 E. Dobrzyńska-Lankosz, Czasopisma szkół wyższych $w$ wolnym dostępie, [w:] Otwarte zasoby wiedzy: nowe zadania uczelni i bibliotek $w$ rozwoju komunikacji naukowej, Kraków, Zakopane, 15-17 czerwiec 2011, praca zbiorowa pod red. M. M. Górskiego i M. Marcinek, Kraków 2011, s. 77-90; A. Drabek, Polskie czasopisma Open Access - próba charakterystyki, „Biblioteca Nostra” 2009, nr 3-4, s. 43-54.

${ }^{5}$ M. Garbacz, K. Moskwa, H. Niemiec, Krajowe czasopisma Open Access [online]. E-LIS. E-prints in library and information science [dostęp 31 marca 2017]. Dostępny w World Wide Web: http://eprints.rclis.org/12754/1/garbacz_moskwa_niemiec.pdf. 
dostępu. Dwie ostatnie kwestie korespondują z badaniami opublikowanymi w niniejszym tekście, choć ówcześnie jedynie jedno czasopismo spośród wszystkich 50 analizowanych tytułów posiadało deklarację licencji Creative Commons ${ }^{6}$. Autorka uznała zatem za zasadne zbadanie polityki otwartości polskich czasopism indeksowanych w DOAJ w zakresie polityki otwartości wyrażonej systemami licencjonowania treści.

Od 10 października do 10 listopada 2016 r. pobrano dane o polskich czasopismach z katalogu Directory of Open Access Journal. Dane te zawierają informacje o liczbie indeksowanych w katalogu polskich czasopism (warunek: kraj publikacji - Polska) oraz licencjach prawnych stosowanych przez czasopismo, językach publikowania, procesie recenzji, kosztach przyjęcia do druku, tematyce oraz formie rekordu czasopisma. Następnie dokonano ich porównania z wdrożoną w 2014 r. w DOAJ nową polityką otwartości oraz sugestiami dotyczącymi publikowania otwartego zawartymi w dokumencie opublikowanym przez MNiSW.

\section{Stara i nowa polityka otwartości DOAJ - konsekwencje dla polskich czasopism ofwartych}

Directory of Open Access Journal jest największym i autorytatywnym międzynarodowym źródłem informacji o czasopiśmiennictwie otwartym, co było główną przyczyną wyboru tego katalogu do badań. Ponadto polskie czasopisma są w nim indeksowane od początku istnienia katalogu. W roku założycielskim (2003 r.) na 300 zaindeksowanych czasopism $^{7} 9$ stanowiły tytuły polskie ${ }^{8}$. W kolejnych latach liczba polskich czasopism indeksowanych w DOAJ rosła, co wykazane zostało w tabeli 1 i na wykresie 1. Spadek odnotowano dopiero w 2016 r. - jego przyczyny zostaną wyjaśnione w dalszej części tekstu.

6 Tamże.

7 T. Olijhoek, D. Mitchell, L. Bjørnshauge, Criteria for open access and publishing. „ScienceOpen Research” [online] 16 November 2015 [dostęp 31 marca 2017]. Dostępny w World Wide Web: https://www.scienceopen.com/document?vid=2befee62-f9c0-4dc893c5-790d6102877d.

${ }^{8}$ B. Bednarek-Michalska, dz. cyt. 


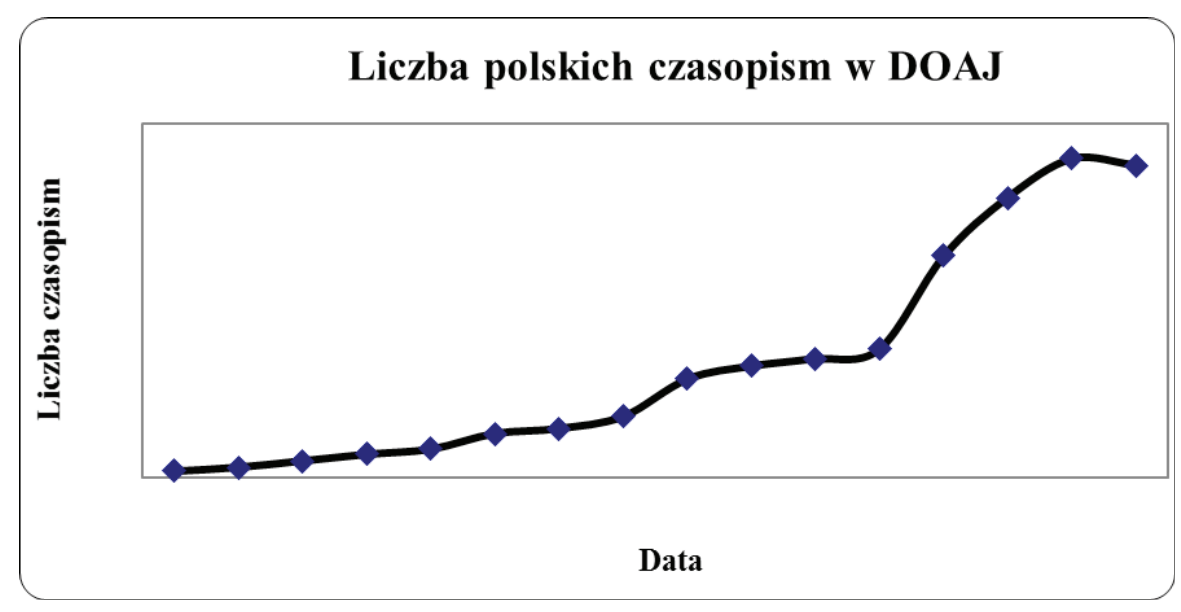

Wykres 1. Liczba polskich czasopism indeksowanych w DOAJ w kolejnych latach istnienia katalogu

Źródło: opracowanie własne na podstawie B.Bednarek-Michalska, Kalendarium OA w Polsce [online] [dostęp 31 marca 2017]. Dostępny w World Wide Web: http://uwolnijnauke.pl/kalendarium-oa-w-polsce oraz danych podawanych w katalogu DOAJ (http://doaj.org) w kwietniu, maju i listopadzie 2016 r.

Tabela 1. Liczba polskich czasopism indeksowanych w DOAJ w kolejnych latach od powstania katalogu

\begin{tabular}{|c|c|}
\hline Rok & Liczba polskich czasopism w DOAJ \\
\hline 2003 & 9 \\
\hline 2004 & 13 \\
\hline 2005 & 21 \\
\hline 2006 & 30 \\
\hline 2007 & 37 \\
\hline 2008 & 56 \\
\hline 2009 & 62 \\
\hline 2010 & 78 \\
\hline 2011 & 126 \\
\hline 2012 & 142 \\
\hline 2013 & 151 \\
\hline
\end{tabular}


Tabela 1. Liczba polskich czasopism indeksowanych cd.

\begin{tabular}{|c|c|}
\hline Rok & Liczba polskich czasopism w DOAJ \\
\hline 2014 & 164 \\
\hline 2015 & 282 \\
\hline styczeń 2016 & 356 \\
\hline maj 2016 & 406 \\
\hline listopad 2016 & 397 \\
\hline
\end{tabular}

Źródło: opracowanie własne na podstawie B. Bednarek-Michalska, Kalendarium OA w Polsce [online] [dostęp: 31 marca 2017]. Dostępny w World Wide Web: http://uwolnijnauke.pl/kalendarium-oa-w-polsce oraz danych podawanych w katalogu DOAJ (http://doaj.org) w kwietniu, maju i listopadzie 2016 r.

Od początku istnienia katalogu definicja otwartości czasopisma była dość szeroka - za czasopisma wydawane w modelu open access przyjmowano te, których model biznesowy nie przewidywał pobierania od czytelników żadnych opłat za korzystanie z udostępnionych treści (co odpowiada dzisiejszemu modelowi gratis), a uzupełnieniem była definicja przyjęta w „Deklaracji Budapesztańskiej”, w której z otwartym dostępem wiąże się prawo użytkowników do czytania, pobierania, kopiowania, dystrybucji, drukowania, wyszukiwania i odsyłania do pełnych tekstów ${ }^{9}$. Wykracza to poza użytek gratis i umieszcza tę wczesną definicję bliżej modelu libre. Od 2003 do połowy 2014 r. indeksowanie czasopism w DOAJ opierało się na uproszczonych kryteriach jakościowych ${ }^{10}$. W maju 2014 r. opracowano i wdrożono stopniowo nowe kryteria jakościowe oparte na Zasadach przejrzystości i dobrych praktyk publikowania naukowego, których ostateczną wersję przyjęto w czerwcu 2015 r. $^{11}$

${ }^{9}$ About DOAJ [18.06.2003] [online] [dostęp 31 marca 2017]. Dostępny w World Wide Web: https://web.archive.org/web/20030618051705/http://www.doaj.org/articles/about/\#definitions.

${ }^{10}$ Por. np. About DOAJ [4.12.2005] [dostęp 31 marca 2017]. Dostępny w World Wide Web: https://web.archive.org/web/20051204062638/http://www.doaj.org/articles/ about.

11 Principles of Transparency and Best Practice in Scholarly Publishing [online] [dostęp 31 marca 2017]. Dostępny w World Wide Web: https://doaj.org/bestpractice. 
W tabeli 2 zestawiono wczesne wytyczne dotyczące indeksowania czasopism w DOAJ (lata 2003-2014 z małymi zmianami) i minimalne kryteria indeksowania czasopism po wdrożeniu Zasad przejrzystości...

Tabela 2. Porównanie warunków indeksowania czasopism w DOAJ przed wprowadzeniem i po wprowadzeniu Zasad przejrzystości i dobrych praktyk publikowania naukowego

\begin{tabular}{|c|c|c|}
\hline Nazwa warunku & $\begin{array}{c}\text { Uśrednione warunki } \\
\text { indeksowania czasopism } \\
\text { w DOAJ w l. 2003-2014 }\end{array}$ & $\begin{array}{c}\text { Minimalne kryteria } \\
\text { indeksowania czasopism } \\
\text { w DOAJ po wdrożeniu Zasad } \\
\text { przejrzystości... w } 2014 \text { r. do } \\
\text { listopada } 2016 \text { r. }\end{array}$ \\
\hline Zakres & $\begin{array}{l}\text { Wszystkie periodyki naukowe } \\
\text { ze wszystkich dziedzin wiedzy } \\
\text { publikujące pełne teksty. Do- } \\
\text { puszczalne wszystkie języki. }\end{array}$ & $\begin{array}{l}\text { Wszystkie periodyki naukowe ze } \\
\text { wszystkich dziedzin wiedzy publi- } \\
\text { kujące pełne teksty. Dopuszczalne } \\
\text { wszystkie języki. Czasopismo musi } \\
\text { posiadać numer ISSN. }\end{array}$ \\
\hline $\begin{array}{l}\text { Akceptowane } \\
\text { źródła danych }\end{array}$ & $\begin{array}{l}\text { Akademickie, rządowe, ko- } \\
\text { mercyjne, niekomercyjne } \\
\text { prywatne }\end{array}$ & $\begin{array}{l}\text { Akademickie, rządowe, komercyj- } \\
\text { ne, niekomercyjne prywatne }\end{array}$ \\
\hline Odbiorca & Naukowiec, badacz & Naukowiec, badacz. \\
\hline Wymagania & $\begin{array}{l}\text { Zasadnicza część czasopisma } \\
\text { powinna zawierać oryginalne } \\
\text { artykuły naukowe (badawcze), } \\
\text { a całość treści powinna być } \\
\text { zamieszczona w otwartym } \\
\text { dostępie. }\end{array}$ & $\begin{array}{l}\text { Co najmniej jedna trzecia czasopi- } \\
\text { sma powinna zawierać oryginalne } \\
\text { artykuły naukowe (badawcze), } \\
\text { a całość treści powinna być za- } \\
\text { mieszczona w otwartym dostępie. }\end{array}$ \\
\hline Otwarty dostęp & $\begin{array}{l}\text { Darmowy dla użytkowników } \\
\text { i instytucji; czasopismo może } \\
\text { być zaindeksowane, jeśli wy- } \\
\text { maga od użytkownika bezpłat- } \\
\text { nej rejestracji przy dostępie } \\
\text { do treści; nie indeksuje się } \\
\text { czasopism mających embargo } \\
\text { czasowe (opóźniony dostęp) } \\
\text { do całości treści. }\end{array}$ & $\begin{array}{l}\text { Cała treść czasopisma powinna } \\
\text { być dostępna darmowo bez em- } \\
\text { barga czasowego, opłaty za dostęp } \\
\text { mogą dotyczyć wersji drukowanej. } \\
\text { Od sierpnia } 2016 \text { r. czasopisma } \\
\text { wymagające bezpłatnej rejestracji } \\
\text { przy dostępie do treści nie mogą } \\
\text { być indeksowane w DOAJ (poli- } \\
\text { tyka ta jest komunikowana także } \\
\text { wydawcom, których czasopisma } \\
\text { są zaindeksowane w DOAJ). Infor- } \\
\text { macje o otwartym dostępie muszą } \\
\text { być precyzyjne. }\end{array}$ \\
\hline
\end{tabular}


Tabela 2. Porównanie warunków indeksowania czasopism cd.

\begin{tabular}{|c|c|c|}
\hline Nazwa warunku & $\begin{array}{c}\text { Uśrednione warunki } \\
\text { indeksowania czasopism } \\
\text { w DOAJ w l. 2003-2014 }\end{array}$ & $\begin{array}{c}\text { Minimalne kryteria } \\
\text { indeksowania czasopism } \\
\text { w DOAJ po wdrożeniu Zasad } \\
\text { przejrzystości... w } 2014 \text { r. do } \\
\text { listopada } 2016 \text { r. }\end{array}$ \\
\hline Otwarty dostęp & & $\begin{array}{l}\text { Lakoniczna, skrótowa informacja } \\
\text { o otwartym dostępie możliwa jest } \\
\text { tylko w przypadku, kiedy czasopi- } \\
\text { smo ukazuje się na jednej z licencji } \\
\text { Creative Commons, o czym jasno } \\
\text { i przejrzyście informuje użytkow- } \\
\text { ników. }\end{array}$ \\
\hline Metadane & $\begin{array}{l}\text { Podstawowe informacje } \\
\text { o tytule }\end{array}$ & $\begin{array}{l}\text { Kryterium to nie należy do mi- } \\
\text { nimalnych wymagań - istnieją } \\
\text { tu jedynie wskazówki. Jednak } \\
\text { ankieta rejestracyjna zbiera dużo } \\
\text { informacji o czasopiśmie, są one } \\
\text { szczegółowe, poparte odsyłaczami } \\
\text { do poszczególnych części witryny } \\
\text { czasopisma. Czasopisma mogą } \\
\text { być indeksowane na dwóch po- } \\
\text { ziomach - jako tytuł i jako czaso- } \\
\text { pismo dostarczające metadanych } \\
\text { o artykułach - są one wówczas } \\
\text { indeksowane w katalogu. }\end{array}$ \\
\hline Jakość & $\begin{array}{l}\text { Czasopismo powinno być pod- } \\
\text { dawane jednej z procedur - } \\
\text { recenzji redakcyjnej (editorial } \\
\text { review) lub zewnętrznemu } \\
\text { procesowi recenzji (peer re- } \\
\text { view). }\end{array}$ & $\begin{array}{l}\text { Wytyczne dotyczą przejrzystości } \\
\text { strony WWW czasopisma i infor- } \\
\text { macji wymaganych. Czasopismo } \\
\text { powinno posiadać dedykowaną } \\
\text { stronę internetową. Informacje } \\
\text { wymagane to: } \\
\text { - } \quad \text { cele i zakres czasopisma, } \\
\text { - } \quad \text { informacje o redaktorze na- } \\
\quad \text { czelnym i redakcji (aktualne } \\
\text { informacje o nazwiskach } \\
\text { i funkcjach członków redak- } \\
\text { cji, afiliacje, adresy e-mail), } \\
\text { - instrukcje dla autorów } \\
\text { - } \quad \text { informacje o wszelkich opła- } \\
\text { tach pobieranych od autorów } \\
\text { w procesie przygotowania } \\
\text { i publikacji (także o ich do- } \\
\text { kładnej wysokości), }\end{array}$ \\
\hline
\end{tabular}


Tabela 2. Porównanie warunków indeksowania czasopism cd.

\begin{tabular}{|c|c|c|}
\hline Nazwa warunku & $\begin{array}{c}\text { Uśrednione warunki } \\
\text { indeksowania czasopism } \\
\text { w DOAJ w l. 2003-2014 }\end{array}$ & $\begin{array}{c}\text { Minimalne kryteria } \\
\text { indeksowania czasopism } \\
\text { w DOAJ po wdrożeniu Zasad } \\
\text { przejrzystości... w } 2014 \text { r. do } \\
\text { listopada } 2016 \text { r. }\end{array}$ \\
\hline Jakość & & 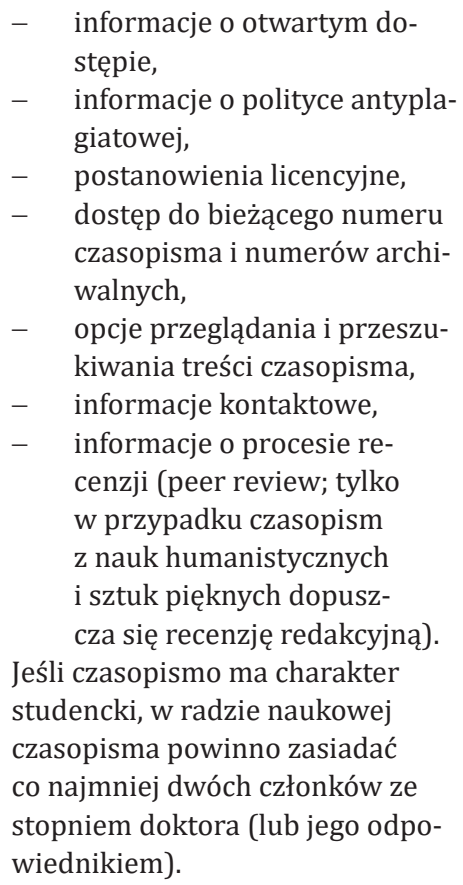 \\
\hline
\end{tabular}

Źródło: opracowanie własne na podstawie archiwalnych wersji witryny DOAJ w latach 2003-2014 dostępnych w serwisie Archive.org (http://archive.org) oraz Information for publishers [online] [dostęp 31 marca 2017]. Dostępny w World Wide Web: https://doaj.org/publishers\#applying.

W oparciu o Zasady publikowania... i nowe wytyczne indeksowania czasopism stworzono w DOAJ nową ankietę aplikacyjną i reaplikacyjną dla czasopism ${ }^{12}$. Składa się ona z 54 pytań podzielonych na pięć sekcji:

12 Journal Application Form [online] [dostęp 31 marca 2017]. Dostępny w World Wide Web: https://doaj.org/application/new. 
1. Podstawowe informacje o czasopiśmie - 35 pytań;

2. Jakość i przejrzystość procesu redakcyjnego - 8 pytań;

3. Rodzaj polityki open Access, jaką stosuje czasopismo - 1 pytanie;

4. Licencjonowanie treści - 7 pytań;

5. Prawo autorskie i uprawnienia - 3 pytania (tej sekcji nie było w pierwszym formularzu ankiety z 2014 r., dodano ją po opublikowaniu nowszej wersji Zasad... latem 2015 r. $^{13}$ ).

Szóstą sekcją w formularzu jest notatka informująca o kryteriach dobrych praktyk otwartościowych przyjętych przez DOAJ. Ich spełnienie uprawnia czasopismo do otrzymania znaku DOAJ (DOAJ Seal). Znak ten został stworzony dla promowania najlepszych czasopism wdrażających zasady publikowania otwartego.

Tabela 3. Zestawienie informacji o liczbie czasopism polskich w DOAJ stosujących lub niestosujących otwarte systemy licencjonowania treści

\begin{tabular}{|c|c|c|c|}
\hline & Ogółem & $\begin{array}{c}\text { Indeksowane } \\
\text { wg nowych zasad }\end{array}$ & $\begin{array}{c}\text { Indeksowane } \\
\text { wg starych zasad }\end{array}$ \\
\hline $\begin{array}{l}\text { Liczba czasopism polskich } \\
\text { w DOAJ }\end{array}$ & 397 & 298 & 99 \\
\hline $\begin{array}{c}\text { Liczba czasopism ze } \\
\text { wszystkimi licencjami } \\
\text { udostępniania treści }\end{array}$ & 338 & 298 & 40 \\
\hline $\begin{array}{l}\text { Liczba czasopism na licencji } \\
\text { CC BY NC ND }\end{array}$ & 233 & 230 & 3 \\
\hline $\begin{array}{l}\text { Liczba czasopism na } \\
\text { licencji CC BY }\end{array}$ & 60 & 30 & 30 \\
\hline $\begin{array}{l}\text { Liczba czasopism na licencji } \\
\text { CC BY NC SA }\end{array}$ & 15 & 13 & 2 \\
\hline $\begin{array}{l}\text { Liczba czasopism na licencji } \\
\text { CC BY NC }\end{array}$ & 12 & 9 & 3 \\
\hline $\begin{array}{l}\text { Liczba czasopism na licencji } \\
\text { CC BY ND }\end{array}$ & 7 & 6 & 1 \\
\hline $\begin{array}{c}\text { Liczba czasopism na licencji } \\
\text { własnej wydawcy }\end{array}$ & 5 & 5 & 0 \\
\hline
\end{tabular}

13 T. Olijhoek i in., dz. cyt. 
Tabela 3. Zestawienie informacji o liczbie czasopism polskich cd.

\begin{tabular}{|c|c|c|c|}
\hline & Ogółem & $\begin{array}{c}\text { Indeksowane } \\
\text { wg nowych zasad }\end{array}$ & $\begin{array}{c}\text { Indeksowane } \\
\text { wg starych zasad }\end{array}$ \\
\hline $\begin{array}{c}\text { Liczba czasopism na } \\
\text { licencji CC BY SA }\end{array}$ & $\mathbf{3}$ & $\mathbf{3}$ & $\mathbf{0}$ \\
\hline $\begin{array}{c}\text { Liczba czasopism na innej } \\
\text { licencji (nie CC) }\end{array}$ & 3 & 2 & 1 \\
\hline $\begin{array}{c}\text { Liczba czasopism bez } \\
\text { licencji }\end{array}$ & 1 & 0 & 58 \\
\hline $\begin{array}{c}\text { Liczba czasopism bez } \\
\text { zadeklarowanej licencji }\end{array}$ & 58 & 0 & 1 \\
\hline
\end{tabular}

\section{LEGENDA:}

czcionka pogrubiona - czasopisma publikowane na wolnych licencjach Creative Commons (licencje te wskazywane są jako rekomendowane przez Ministerstwo Nauki i Szkolnictwa Wyższego w cytowanym już dokumencie Kierunki rozwoju...).

- czasopisma publikowane na licencjach CC wskazanych przez DOAJ jako spełniających najwyższe standardy otwartości i będące jednym z warunków przyznania odznaki DOAJ Seal

Źródło: opracowanie własne na podstawie danych o polskich czasopismach w DOAJ pozyskanych 12 listopada 2016 r. z witryny www.doaj.org.

Konsekwencją wprowadzenia w DOAJ nowych kryteriów indeksowania i nowej ankiety aplikacyjnej było wezwanie do złożenia nowych ankiet reaplikacyjnych wszystkich czasopism zaindeksowanych w DOAJ przed 2014 r. Przedłużonym i ostatecznym terminem składania reaplikacji był 31 marca 2016 r. Czasopisma, które nie złożyły ankiety w tym terminie, zostały usunięte z bazy. Nastąpiło to na początku maja $2016 \mathrm{r}$. Największa liczba czasopism polskich indeksowanych w bazie odnotowana 5 maja 2016 r. wynosiła 406 tytułów. Po 5 maja 2016 r. liczba ta spadła o ok. 25-30 tytułów po usunięciu rekordów czasopism, które nie złożyły reaplikacji. Stan na 20 listopada 2016 r. to 397 czasopism polskich indeksowanych w bazie. Należy tu odnotować, że nie wszystkie czasopisma spośród tytułów wydawanych w Polsce to czasopisma zaindeksowane po weryfikacji ankiet reaplikacyjnych - polskich czasopism niezweryfikowanych (stan na dzień 20.11.2016 r.) jest 99. 
Prześledzono, jak kształtuje się stosowanie licencji Creative Commons i licencji własnych wydawców wśród grupy czasopism polskich indeksowanych w DOAJ. Dane te zaprezentowano w tabeli 3.

\section{Wnioski}

Z tabeli 3 wynika, że spośród wszystkich 397 czasopism polskich indeksowanych w DOAJ 338 objętych jest licencjami. Stanowi to ok. 85,1\%, w tym ok. 15,1\% (60 czasopisma) objętych jest całkowicie wolnymi licencjami CC, a ok. 18,9\% (75 czasopism) stanowią czasopisma na licencjach rekomendowanych przez DOAJ. W grupie czasopism objętych nowymi zasadami indeksowania 100\% czasopism objętych jest licencjami, co nie dziwi, gdyż jest to minimalny warunek indeksowania czasopisma w katalogu. Zaledwie ok. 0,67\% (2 tytuły) stanowią czasopisma licencjonujące treści innym systemem licencji niż CC. Warto zauważyć, że w tej grupie czasopism wskaźniki czasopism na licencjach otwartych i DOAJ są niższe niż ogółem dla wszystkich polskich czasopism indeksowanych w katalogu - odpowiednio stanowią ok. 11,1\% (33 tytuły) oraz 14,1\% (42 tytuły) wszystkich czasopism indeksowanych po wprowadzeniu nowych wymagań. Wartości te inaczej rozkładają się wśród 99 czasopism polskich, które nie zostały zaindeksowane jeszcze według nowych zasad, a ich ankiety reaplikacyjne czekają na weryfikację. Wśród 99 takich periodyków 40 jest objętych systemem licencji, co stanowi ok. 40,4\%. W tej grupie ok. 30,3\% (30 tytułów) objętych jest wolnym systemem licencji, a w przybliżeniu 33,3\% licencjami rekomendowanymi przez DOAJ.

\section{Podsumowanie}

W grupie czasopism polskich wskaźnik objęcia licencjami jest bardzo wysoki i z pewnością będzie rósł, gdyż stosowanie przez czasopisma systemu licencji CC lub innego jest minimalnym warunkiem wymaganym przez DOAJ przy indeksowaniu. Mogą się tu realizować dwa scenariusze czasopism polskich może nieco ubywać, jeśli złożone przez nie ankiety reaplikacyjne nie wypełniają minimalnych warunków indeksowania w DOAJ w zakresie licencji lub innych kryteriów. Może też się okazać, 
że czasopisma wcześniej nie posiadające licencji wprowadziły system licencjonowania treści - wówczas periodyków polskich będzie w DOAJ jedynie przybywać. Widać także tendencję do obejmowania czasopism licencjami o warunkach bardziej restrykcyjnych. Dominującą licencją w grupie periodyków wydawanych w Polsce jest licencja CC BY-NC-ND (CC uznanie autorstwa - użycie niekomercyjne - bez utworów zależnych), która jest najbardziej restrykcyjną licencją CC i bliżej jej do modelu gratis niż libre. Należy tu także zauważyć, że największym wydawcą polskich czasopism indeksowanych w DOAJ jest De Gruyter Open - aż 223 tytuły (ok. 56,2\% całości periodyków polskich w DOAJ). Wśród nich wszystkie objęte są licencjami CC, w tym: 198 tytułów to czasopisma objęte licencją CC BY-NC-ND, a 16 licencją CC BY (tylko jedno czasopismo w tej grupie zostało zaindeksowane według nowych zasad). Jest to kolejna przesłanka do wnioskowania, że czasopisma naukowe wydawane w Polsce i indeksowane w DOAJ są otwarte, ale polityce wydawców czasopism w otwartym dostępie bliżej do modelu gratis niż do modelu libre. Należy zadać więc sobie pytanie, czy rekomendacje MNiSW co do licencji wartościowych z punktu widzenia polityki otwartości zmienią sytuację na rynku polskich czasopism naukowych, czy też pozostaną wyłącznie sugestią. Pozostawia to pole do dalszych badań rozwoju modelu komunikacji naukowej w Polsce w zakresie czasopism otwartych.

\section{Bibliografia}

About DOAJ [18.06.2003] [online] [dostęp 31 marca 2017]. Dostępny w World Wide Web: https://web.archive.org/web/20030618051705/http://www. doaj.org/articles/about/\#definitions.

About DOAJ [4.12.2005] [dostęp 31 marca 2017]. Dostępny w World Wide Web: https://web.archive.org/web/20051204062638/http://www.doaj.org/ articles/about.

Bednarek-Michalska Bożena, Kalendarium OA w Polsce [online] [dostęp 31 marca 2017]. Dostępny w World Wide Web: http://uwolnijnauke.pl/kalendarium-oa-w-polsce.

Dobrzyńska-Lankosz Ewa, Czasopisma szkół wyższych w wolnym dostępie, [w:] Otwarte zasoby wiedzy: nowe zadania uczelni i bibliotek $w$ rozwoju komunikacji naukowej, Kraków, Zakopane, 15-17 czerwiec 2011, praca zbiorowa pod red. Marka M. Górskiego i Marzeny Marcinek, Kraków 2011, s. 77-90. 
Drabek Aneta, Polskie czasopisma Open Access - próba charakterystyki, „Biblioteca Nostra" 2009, nr 3-4, s. 43-54.

Garbacz Mirosław, Moskwa Krzysztof, Niemiec Honorata, Krajowe czasopisma Open Access [online]. E-LIS. E-prints in library and information science [dostęp 31 marca 2017]. Dostępny w World Wide Web: http://eprints.rclis. org/12754/1/garbacz_moskwa_niemiec.pdf.

Journal Application Form [online] [dostęp 31 marca 2017]. Dostępny w World Wide Web: https://doaj.org/application/new.

Kierunki rozwoju otwartego dostępu do publikacji i wyników badań naukowych w Polsce [online]. Warszawa: Ministerstwo Nauki i Szkolnictwa Wyższego, 2016, 20 s. [dostęp 31 marca 2017]. Dostępny w World Wide Web: http:// www.nauka.gov.pl/g2/oryginal/2016_09/25db3413b93e0da2c7c862a80e 687ad1.pdf.

Olijhoek Tom, Mitchell Dominic, Bjørnshauge Lars, Criteria for open access and publishing. „ScienceOpen Research” [online] 16 November 2015 [dostęp 31 marca 2017]. Dostępny w World Wide Web: https://www.scienceopen. com/document?vid=2befee62-f9c0-4dc8-93c5-790d6102877d.

Principles of Transparency and Best Practice in Scholarly Publishing [online] [dostęp 31 marca 2017]. Dostępny w World Wide Web: https://doaj.org/ bestpractice.

Suber Peter, Otwarty dostęp, Warszawa 2014.

Timeline before 2000 [online] [dostęp 31 marca 2017]. Dostępny w World Wide Web: http://oad.simmons.edu/oadwiki/Timeline_before_2000.

\section{Openness of Polish Periodicals Indexed in DOAJ - Towards the Gratis or Libre Model?}

ABstract: Open access to scientific content means removal of cost barriers and most of the restrictions on copyright laws. It can have a gratis dimension, where the elimination of the cost is the only manifestation of openness and usage is limited to fair use. It may also take the form of access known as libre, which, through the introduction of a license system, appoints possibilities of usage beyond fair use. The article investigates the situation of Polish research periodicals registered in the Directory of Open Access Journal for the application of license recommended in DOAJ and by Ministry of Science and Higher Educa- 
tion of Republic of Poland. The aim was to answer a question which model of openness - gratis or libre - is closer to Polish journal publishers.

KEYworDS: Creative Commons licences, Directory of Open Access Journals, DOAJ, open access, open access gratis, open access libre, Polish research journals. 